\title{
Endoscopic management of chronic pancreatitis with a fully covered self-expanding metal stent and laser lithotripsy
}

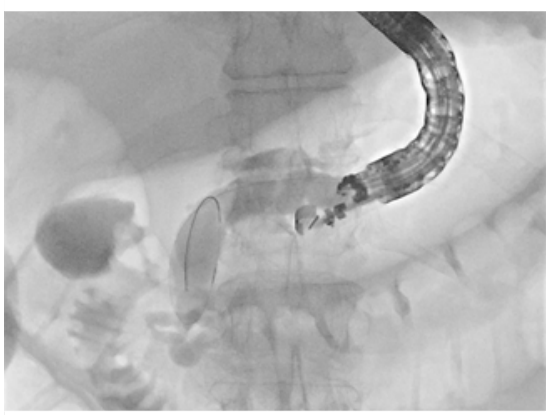

- Fig. 1 Echoendoscope with a guidewire in a dilated pancreatic duct that is being injected with contrast. Transpapillary access for placement of a fully covered metal stent had not been successful in this patient with chronic pancreatitis and pancreatic duct stones.

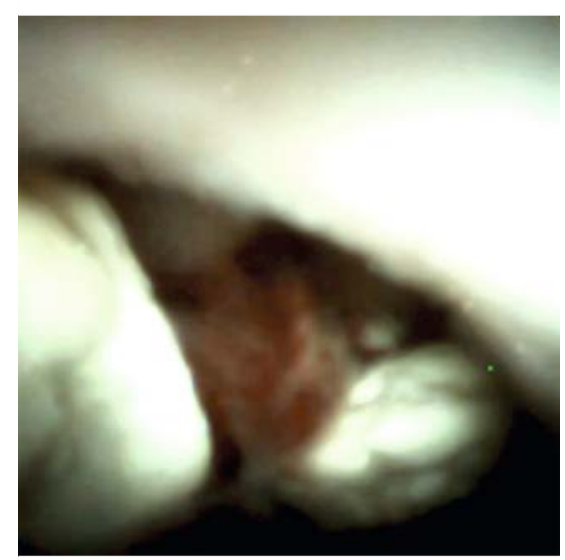

- Fig. 2 Pancreatoscopy shows two of the pancreatic duct stones inside the dilated pancreatic duct, before initiation of laser lithotripsy.

The patient was a 58-year-old man with a long-standing history of alcohol abuse and chronic pancreatitis leading to multiple hospitalizations. He continued to have pain despite conservative management, pain control, and alcohol cessation. His chronic pancreatitis and pancreatic duct (PD) stones resulted in a tight PD stricture at the head of the pancreas. Multiple prior attempts at conventional endoscopic retrograde cholangiopancreatography (ERCP) had failed. He pre-



Video 1 Endoscopic ultrasound-guided access into the main pancreatic duct, with placement of a fully covered metal stent creating a pancreaticogastrostomy. In a repeat procedure, access via the pancreaticogastrostomy was used to perform laser lithotripsy of pancreatic stones.

sented to our institution seeking advanced therapy after extracorporeal shock wave lithotripsy (ESWL). At our index ERCP we could not get conventional transpapillary access to the PD. Instead, given his stone burden, after ESWL, we chose to treat him with an EUS-guided pancreaticogastrostomy, and placement of a fully covered self-expanding metal stent (FCSEMS) followed by a pancreatoscopy with holmium laser lithotripsy ( Fig. 1 and $>$ Fig.2). The patient responded to treatment, with resolution of his pain at 12 months after the intervention.

In chronic pancreatitis, chronic inflammation causes endocrine and exocrine insufficiency, pancreatic atrophy, calcification, and multiple pancreatic duct strictures that lead to chronic pain [1]. This chronic disease has much associated morbidity. Current therapies include pain control and supportive measures aimed at treatment of endocrine and exocrine insufficiencies. PD strictures and PD stones frequently accompany chronic pancreatitis. Endoscopic management of chronic pancreatitis includes ERCP with transpapillary plastic stent placement, PD balloon dilation, and ESWL for PD stones. FCSEMS placement has been reported as a treatment for refractory $\mathrm{PD}$ strictures in patients in whom other therapeutic modalities have failed [2]. However, in the patient described here, a conventional transpapillary ERCP approach for placement of the FCSEMS was not successful, and we used an EUS-guided technique to place an FCSEMS, and we then used this access for laser lithotripsy [3].

EUS-guided pancreaticogastrostomy is an option when conventional transpapillary stent placement is not possible. This case illustrates that pancreaticogastrostomy can be used as access for laser lithotripsy.

Endoscopy_UCTN_Code_TTT_1AR_2AI 
Michel Kahaleh MD has received grant support from Boston Scientific, Fujinon, EMcison, Xlumena Inc., W.L. Gore, MaunaKea, Apollo Endosurgery, Cook Endoscopy, ASPIRE Bariatrics, Gl Dynamics, NinePoint Medical, Merit Medical, Olympus and MI Tech. He is a consultant for Boston Scientific, Xlumena Inc., Concordia Laboratories Inc, ABBvie, and MaunaKea Tech. All other authors have no conflicts of interest to report.

The Authors

Aleksey Novikov, Ming-ming Xu, Amy Tyberg, Michel Kahaleh

Weill Cornell Medical, New York, USA
Corresponding author

\section{Michel Kahaleh, MD}

Weill Cornell Medical College -

Gastroenterology \& Hepatology, 1305 York Avenue, 4th Floor, New York 10021, United States

Fax: +1-646-962-0110

mkahaleh@gmail.com

\section{References}

[1] Majumder S, Chari TS. Chronicpancreatitis. Lancet 2016; 387: 1957-1966 (doi:10.1016/S0140-6736(16)00097-0) Epub 2016 Mar 2

[2] Kahaleh M, Brijbassie A, Sethi A et al. Multicenter trial evaluating the use of covered self-expanding metal stents in benign biliary strictures: time to revisit our therapeutic options? J Clin Gastroenterol 2013; 47: 695-699
[3] Tyberg A, Sharaiha RZ, Kedia P et al. EUSguided pancreatic drainage for pancreatic strictures after failed ERCP: a multicenter international collaborative study. Gastrointest Endosc 2017; 85: $164-169$

\section{Bibliography}

DOI https://doi.org/10.1055/s-0043-118214

Published online: 19.9.2017

Endoscopy 2017; 49: E296-E297

(c) Georg Thieme Verlag KG

Stuttgart · New York

ISSN 0013-726X

\section{ENDOSCOPY E-VIDEOS}

https://eref.thieme.de/e-videos

回局 Endoscopy E-Videos is a free access online section, reporting 回: on interesting cases and new techniques in gastroenterological endoscopy. All papers include a high quality video and all contributions are freely accessible online.

This section has its own submission website at https://mc.manuscriptcentral.com/e-videos 